\title{
Redefining Human Complexities
}

\author{
Jean-Paul Close
}

STIR Foundation, AiREAS and STIR Academy, Netherlands

Copyright (C) 2015 by authors, all rights reserved. Authors agree that this article remains permanently open access under the terms of the Creative Commons Attribution License 4.0 International License.

\begin{abstract}
From 2010 onwards the first phase of a unique project was initialized in Eindhoven, the Netherlands. It was initiated by the STIR Foundation after many years of trial and error to find a breakthrough into a new societal resonance that would place sustainable human progress at the center of governance and societal productivity. The type of societal resonance was coined "Sustainocracy", an alternative to the democracy that had developed into the destructive consumer capitalism of generalized greed. The ideology refers to the gigantic human issues we face in the world in terms of climate change, pollution, migrations, health hazards, destruction of natural resources, and the vulnerability of huge groups of our global population, due to lack of harmonization with each other or our natural environment. The local solutions of Sustainocracy have been developed around five key human values that have the required harmonizing effect. These values are food (including drinking water), health, safety, regional selfsufficiency and self- awareness, together accounting for the definition of sustainable human progress. In the philosophy of Sustainocracy the four key pillars of local society: government, citizens, entrepreneurial innovators and science, have to take co-responsibility around a predefined higher purpose, within the context of the definition of sustainable human progress. A territory and specific higher purpose was needed to translate the idealistic abstract drive into this first phase of practical deployment. The city of Eindhoven in the Netherlands accepted the invitation when the higher purpose of air quality, human health and regional dynamics was proposed. The human value driven, sustainocratic cooperation was named AiREAS. This article outlines the unique approach and results so far.
\end{abstract}

Keywords STIR Foundation, AiREAS, Sustainable Human Progress, Sustainocracy, Democratic Alternative, Proof of Concept, Eindhoven, Transformation Economy

\section{Introduction}

In the 70 s of the 20 th century, our local and global human communities gradually engaged in the structure of consumption based capitalism ${ }^{1}$. This engagement followed the old industrial era that had reigned for two and a half centuries, ending in world wars due to the structural unbalance in the distribution of wealth between employers, employees and unemployed. Meanwhile the exodus to low wage countries caused a massive increase of the distribution of goods, with a redistribution of global economic development and public involvement. Local governments around the world needed to find ways to fund social securities that would avoid public uprise against the system or radical groups to develop when left outside the consumption patterns. Stimulating and taxing consumption ${ }^{2}$ along with a flexible debt system and a speculative real estate policy, the governments tried to keep their local economies growing. They felt it necessary to fund the consequences of aging and growing populations, remediate the many welfare illnesses of over-consumption, and develop the infrastructures for mass distribution.

Since the start of the new millennium, the 21 st century, the many flaws in this system have been causing all kinds of recessions and depressions. The credit crisis $^{3}$ culminated in the singularity announcing, against the will of powerful money driven resonance, the end of an era. Chaos was ahead. There were two ways to address this insight: fight it or let it go, and define a new societal model. In retrospect, we now can see that this money-based system has stimulated individual and institutional greed reaching unsustainable proportions. It produced vast richness and technological development at the expense of ethical awareness and moral development. In Western societies ethics ${ }^{4}$ has disappeared, so has human cohesion and the spiritual harmony with our natural surroundings. Pollution, climate change, massive migrations, hunger in the world and the disappearance of our eco-system, are powerful indicators of our our own vulnerability in the short term, not just as an economy of growth but also as a species. We are well on the way of

1 Ayn Rand (1957) Atlas Shrugged. United States

2 Ricardo, D. (1817) On the Principles of Political Economy and Taxation. John Murray, London.

${ }_{3}^{3}$ Longstaff (2008) The subprime credit crisis and contagion in financial markets Journal of Financial Economics

${ }^{4}$ Laszlo Zolnai (2015) The spiritual dimension of business ethics and sustainability management . Springer 
destroying ourselves and our habitat. Scientists refer to this human era as the sixth global life destructive force since the birth of our planet, the first produced by a self-aware, intelligent species. This human destructive force is commonly now referred to as the "Anthropocene" ${ }^{5}$, both genetically as environmentally.

This calls for a redefinition of our human complexities, the search for the goodness in our species, a spiritual quest for life enforcement through meaning, purpose and love for life. The global engagement and dependence on competitive consumption based capitalism is so deeply rooted in all fragmented expressions of the system, that it cannot resolve the issues from within without challenging its own system's existence. The enormous distribution of engrained political and economic power positions are desperately trying to sustain themselves in an attempt to uphold the system by avoiding change and even disputing awareness. Meanwhile, the collapse is sensed everywhere, with the danger of a new global destructive conflict. At the same time, other people experiment with new realities and complexities, some in direct confrontation with the Western establishment through uprise or terrorism, others, like Sustainocracy, inviting the world to engage in developing the key human evolutionary values in a new economic position referred to as the "transformation economy" (figure 3 ).

\section{Sustainocracy}

For a long time, democratic freedom has been a highly desired goal for communities in order to develop auto-determination rather than being slave to the dictatorship of a few self proclaimed inherited landowners. Now that we have our freedom of choice, we find that our choices are generally dictated around our self-interests of personal wealth and wellbeing. In a sense we have created a hierarchy around greed with the conservative and competitive desire to maintain at least the status quo through democratic discussion and political coloring. The combination of democracy, consumption driven capitalism and the perceived need for economic growth, has so powerfully engaged the masses that pillars of power have risen around this engagement. Disengagement takes the foundation away of all the hierarchies that depend on it. Disengagement has even been made illegal, contrary to spiritual freedom that has been our birthright. This legal and mental blockage causes a democratic impasse that is continuously shaken by crises and recessions ${ }^{6}$. Despite the known and documented cleansing effect of recessions ${ }^{7}$ we have reached a size of population and engrained dependence on the reigning format that new recessions will not just be cleansing but actually endanger

\footnotetext{
5 PG Crutzen (2006) The "Anthropocene" Springer

6 Rotberg, Robert I. "The New Nature of Nation-State Failure." The Washington Quarterly 25.3 (2002): 85-96.

7 Caballero, Ricardo J., and Mohamad L. Hammour. The cleansing effect of recessions. No. w3922. National Bureau of Economic Research, 1991.
}

our existence. Recessions tend to be expressed in material terms only while the biggest recession seems to occur in the invisible and avoided complexity of moral awareness.

In 2008 this visualization of our moral and organizational complexity (figure 1) was introduced to guide my own thinking processes around "what are we" (including the self reflection "what am I"?) and "what do we do?". It helped me understand the cyclic learning patterns of doing something and subsequently developing ethical awareness after experiencing the consequences. I also learned through personal experiences and enlightening that there is a breakthrough point after which one does not blindly "do", learning "to be" as when painful consequences are experienced and processed rationally. After the breakthrough one calibrates one's actions against a deeper sense of being, a sense of consciousness of the harmony and commitment to living life through a deep sense of responsibility and inner balance. It dawned to me that this spiritual breakthrough is not limited just to the individual but also represents the binding force of stable, successful and harmonic communities. It became my life's mission to prove this point in a phase of society in which this bondage had disappeared, placing the civilization in my own views and sensitivity on the verge of a dramatic collapse yet also at the gateway of a definitive evolutionary gateway to a higher form of society. I asked myself "how can I transform a society from the edge of collapse into one that harmonizes in symbiose within itself and the environment?" This reposition needed a name to resonate with. I called it Sustainocracy, the new democracy in which we place the evolutionary human being at the center of our attention.

Sustainocracy ${ }^{8}$ highlights a common fixed purpose of our species through its own definition of "sustainable human progress": "To keep working together on a healthy, safe, vital, self-aware and self-sufficient human community in close relationship with the ever-changing environment in which live and act". Giving a fixed humanitarian and evolutionary direction to a community, other that the economy of growth, including its harmonization responsibility with its environment, the democratic dialogue starts to alter. Instead of discussing ways to make more money without realizing the consequences, the dialogue and interaction develops around health, safety, self-awareness, quality food and drinking water and self-sufficient productivity through acting together.

In a small country like the Netherlands, the money driven paradigm has concentrated lots of logistics. Through the harbor of Rotterdam millions of containers ${ }^{9}{ }^{10}$ from China and other parts of the world are being shipped to destinations in the whole of Europe. The shipment is by road, train,

\footnotetext{
${ }^{8}$ Jean-Paul Close (2012) Sustainocratie, de nieuwe democratie waarin de mens centraal staat MultiLibris (NL)

9 Baird, Alfred J. "Containerization and the decline of the upstream urban port in Europe." Maritime policy and Management 23.2 (1996): 145-156.

$10 \mathrm{Ng}$, Adolf KY, and Su Song. "The environmental impacts of pollutants generated by routine shipping operations on ports." Ocean \& Coastal Management 53.5 (2010): 301-311.
} 
airplane or riverboats. The consequence is that Central Europe has highly been polluted ${ }^{11}$ from an air quality perspective. Calibrating discussions and decisions against the economy and politics of capitalism, air quality and human health has never been a proactive priority. The World Health Organization declared air pollution ${ }^{12}$ a health hazard of the first degree, meaning that it is lethal. Air pollution kills more people every year in the public space than traffic accidents, in some reports up to 9 times ${ }^{13}$ more. It is not just the killing itself that matters, but also the many years of discomfort and doctors visits that people with lung and heart problems have to endure. Scientific studies reveal that unborn babies ${ }^{14}$ are affected and brain damage occurs producing all kinds of behavioura $1^{15}$ disorders. The societal and natural consequences are huge. However, the engagement with consumption capitalism has been treating the consequences as a cost, with expensive remedial medicines and operations as a solution. The exponential rise of consequences and its costs has got the world leaders to push for more consumption or financial speculation in order to be able to tax and finance the artificial (pharmaceutical or technological) remedies in the hands of powerful lobbies. This is an unsustainable progression because it does not take harmonization with our environment into account, to name just one of the issues at hand, nor its ethics. As many economic interests have grown around the artificial remedies as around the processes that cause the unbalance. Both together produce an even larger tension between money driven activities and our natural harmony and holistic sense ethics. Ethics is often even formally explained as the lawful requirement to sustain the system rather that the spiritual responsibility to harmonize within laws of nature ${ }^{16}$. To introduce a transformative loop, without having to challenge the entire money driven complexity or wait for the overall collapse, the STIR loop was introduced.

From theoretical ideology to practical reality:

Sustainocracy invites institutions to engage with human sustainable progress and co-create value by initiating such loop. The STIR loop (Figure 2) is named after the STIR ${ }^{17}$ Foundation, dedicated to setting up such value driven initiatives. The loop consists of the positioning of a venture

11 Rondinelli, Dennis, and Michael Berry. "Multimodal transportation, logistics, and the environment: managing interactions in a global economy." European Management Journal 18.4 (2000): 398-410.

12 World Health Organization, ed. Global health risks: mortality and burden of disease attributable to selected major risks. World Health Organization, 2009.

13 2013: Chronic exposure to air pollution causes nearly nine times as many premature deaths in Canada as traffic crashes, Univ. of B.C. researchers say in an article in the Canadian Medical Association Journal.

14 Lee, Pei-Chen, et al. "Particulate air pollution exposure and C-reactive protein during early pregnancy." Epidemiology 22.4 (2011): 524-531.

15 van Kempen, Elise, et al. "Neurobehavioral effects of exposure to traffic-related air pollution and transportation noise in primary schoolchildren." Environmental research 115 (2012): 18-25.

16 Zajac, Gary. "Beyond Hammurabi: A public service definition of ethics failure."Journal of Public Administration Research and Theory 6.1 (1996): 145-160.

${ }^{17}$ STIR: Sustainocratic Transformation,Indexation and Research - founded in 2009 by Jean-Paul Close in Eindhoven (NL) within the natural spiritual context of sustainable human progress. The overall sustainocratic ideology is too abstract to be integrally followed by the fragmented authorities of a transaction based economy (see figure 3). In order to get connected with the initiation of the loop an (global) issue of sufficient threat or importance needs to be defined.

The STIR Foundation had been established just after the credit crisis in 2008. Before that, all energy was used to address the transformation of business after redefining business ethics ${ }^{18}$ and responsibilities in various publications ${ }^{19}$ as well as setting up a consultancy group. Business had been spiritually redefined ${ }^{20}$ away from "using humankind and our planet for financial gain to serving humankind and the planet for sustainable progress". Consultancy, however, had become so critical for business that it became unsustainable despite numerous corporate business plans being rewritten according to the proposed ideology. It became obvious that business alone was not up to the task. The resonance to change had to occur at the same time, in parallel, involving public and private interaction, committing together to addressing an issue that has multidisciplinary attention but cannot be solved by any of the fragmented positions of authority alone. As a consequence, the STIR Foundation was founded and based on this new insight of a multidisciplinary approach ${ }^{21}$. The initiative positioned itself holistically as a connecting ethical responsibility above the institutional fragmentation, even the modern attempt of an economy driven popularised corporate interaction referred to as triple helix ${ }^{22}$. During the mayor part of 2009 and 2010, the foundation set up workgroups, organized congresses and seminars around traditional sustainability issues (energy, healthcare, food, mobility, etc.) but could not come to a transformative setting due to tension with the establishment.. In 2010 it was decided to dissolve all groups and take responsibility through the becoming of the first "Sustainocrat", an independent professional that represents the holistically defined sustainocratic values and invites the key players of society to address an issue together. The experimentation had got the sustainocrat to combine air quality with human health and very first measureable point of possible progress to which all kinds of other innovations could be related. A focus had appeared to produce proof of the Sustainocratic and STIR loop principle. The combination of defining Sustainocracy with the human complexities (figure 1), the multidisciplinary harmonization process with our natural environment through the STIR loop (figure 2) and the link of the value driven transformation economy with the transaction economy of growth (figure 3 ) became the working tools for an unprecedented new venture.

\footnotetext{
18 Close, JP "Handboek voor de (toekomstige) Marktleider" Centraal Boekhuis/Move to Holland (2005)

${ }_{19}$ Close, J.P. "Succesgids voor Ondernemers" (2007) Pearson Benelux

${ }^{20}$ Close,J.P. "De 5K MDO Index voor supermarkten", (2008) Move to Holland

${ }^{21}$ Close, J.P. "Geheimen van echte Welvaart", (2009)

22 Etzkowitz, Henry, and Loet Leydesdorff. "The dynamics of innovation: from National Systems and "Mode 2" to a Triple Helix of universityindustry-government relations." Research policy 29.2 (2000): 109-123.
} 


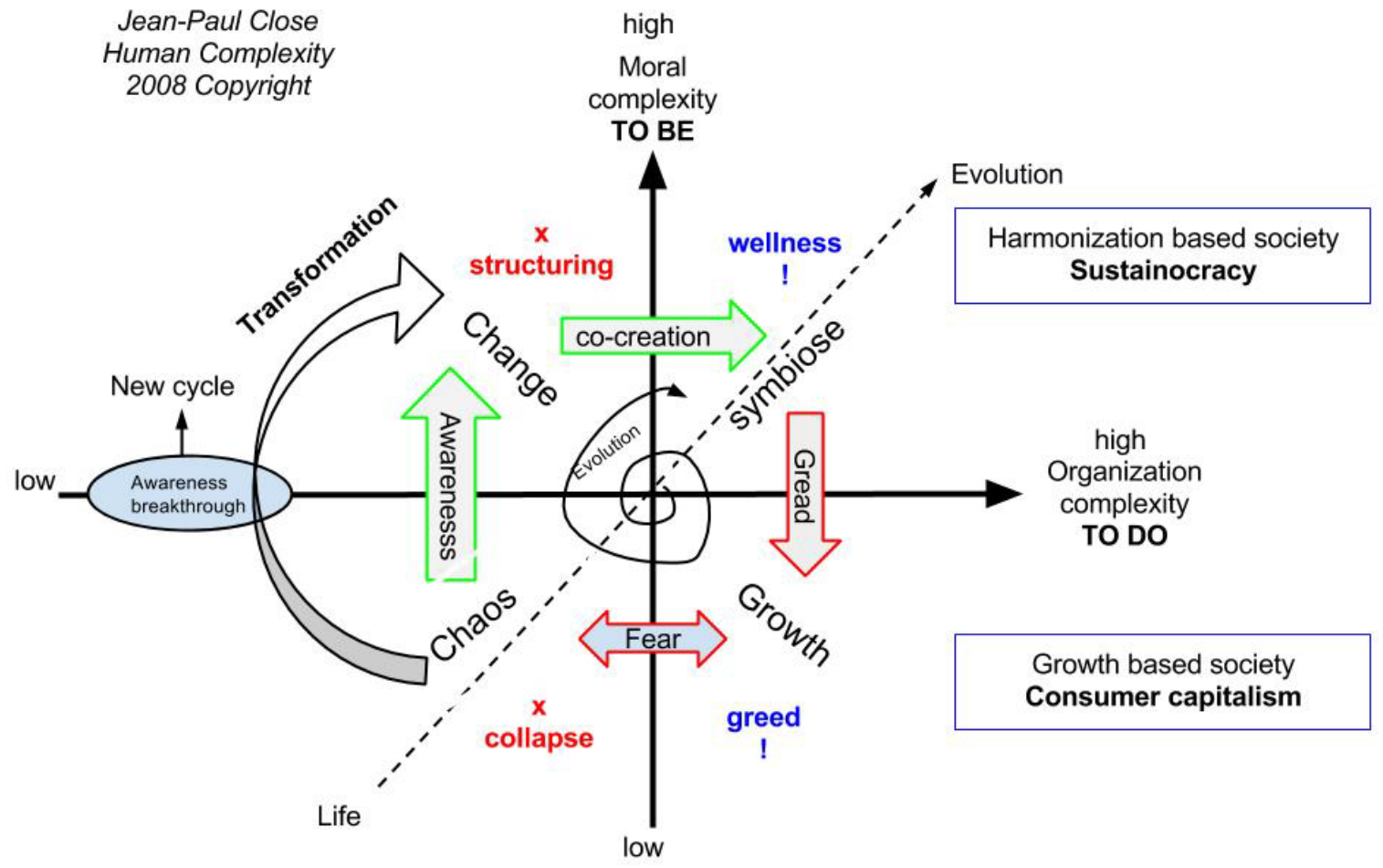

Figure 1. Human complexity visualized in its evolutionary pattern

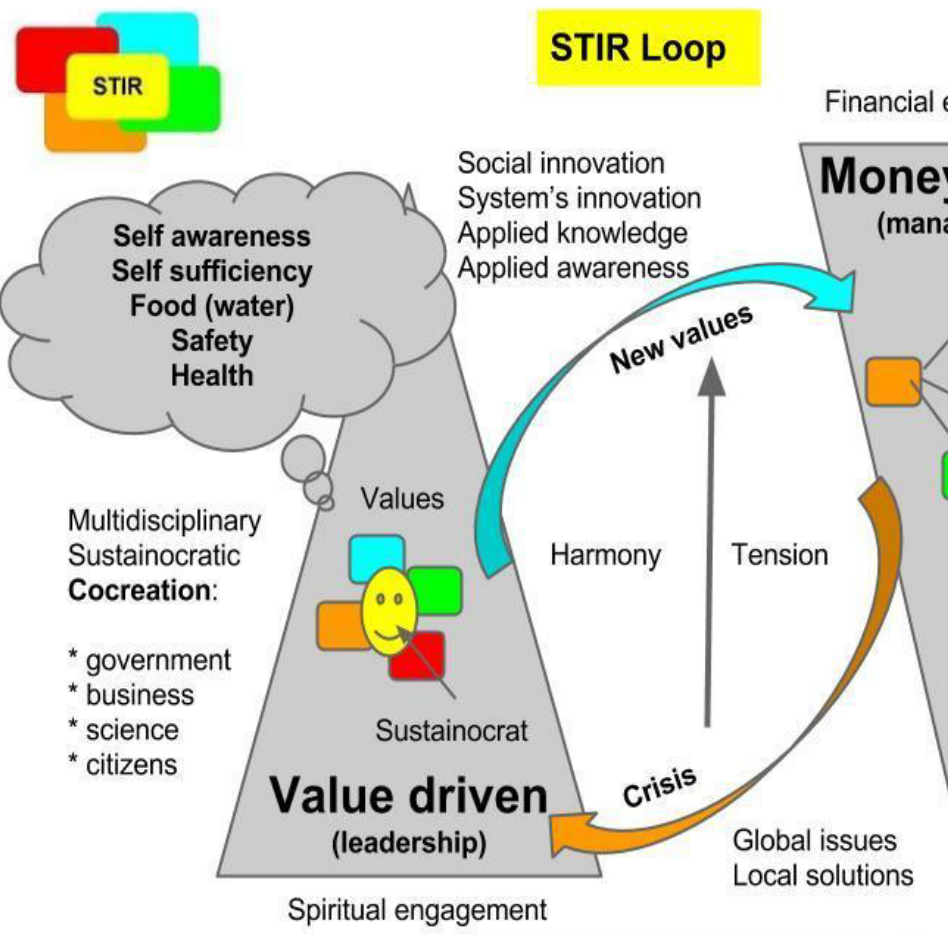

Regional development \& Responsibility

\section{Transformation Economy}

Figure 2. STIR loop visualized 



Figure 3. Spiritual leadership positioned in relation financial management. Positioning STIR foundation with Sustainocracy in the transformation economy it could deal with human and environmental value creation outside the dominance of growth.

When addressing the key authorities (government, business innovators, citizens and scientists) in the city of Eindhoven and Province North Brabant (Netherlands) they all accepted to form a human values driven group around the "healthy city" concept with air quality and human health as innovation markers.

AiREAS (local health, air quality and regional dynamics) was born as a practical and formal next step. This sustainocratic venture is based on the global issue of climate change and health hazards with related local exponential societal costs as produced by air pollution. In the money driven reality the four pillars of society have a financial relationship with seemingly different, often even opposing interests. In joining the Sustainocratic community they all have engaged with the same predefined higher purpose with a mentality around change (see figure 3 ). Together all participants concentrate on developing and implementing a diversity of solutions together. These measurable values are proven against the issue at hand and subsequently integrated and expanded back into the money driven reality of fragmented growth. Hence, value creation has become an societal investment instead of a cost, by producing change that can be measured and reproduced in other areas around the world. The multidisciplinary value creation addresses the issue, not the consequences, involving the diversity of interests and abilities of the community members. Against the perspective of real and visible solutions new political and economical interests can be calibrated.

\section{AiREAS}

The cooperative venture AiREAS (aligning AiR with AREA) invited institutions and resident civilians in the Netherlands to successfully engage with the co-creation of community health and healthy environments instead of curing broken lungs, cardiac arteries or remediating damaged brain cells through expensive health and medical care. The living lab became the city of Eindhoven (Netherlands) with a population of 220.000. The spiritual connection of meaningful cooperation united the city and provincial governments, three key universities specializations (modelling, lung and behavioral research), private researchers (cardio-vascular), civilian groups, and business innovators, all around the inviting sustainocrat. The sustainocrat assures equality between all participants, eliminating temporarily the hierarchies and dependencies that relate them otherwise.

The first multidisciplinary gathering was focused on defining the first priority of the group. Government suggested that we should "visualize the invisible" in order to be able to determine the real origins of air pollutants, its composition, the real exposure of citizens and its effects on our health. If we wanted to observe pollution in public space as close as possible to the civilians that live in and use the city, we would need to create a measurement system as closely as possible to their potential exposure to pollutants. Guided by existing scientific insights, the characteristics and 
distribution of a fine maze, (near) real time, low cost measurement system has been defined. Since none of this technology existed in the entire world the group decided to design and develop it by itself. In October 2012, the formal alliance was made public in the city hall of Eindhoven. In September 2013, the first Airbox was placed on a lamp post in the city, calibrated and validated against the best benchmark systems available and proved to deliver equivalent data. Since then over 10 cases were registered and documented on specific air pollution events and very deep insight has been obtained on pollution patterns and origins. New research projects, including eHealth, clinical measurements, GPS tracking, ultrafine dust exposures, etc have been started as well as proactive actions to stimulate social and applied technological innovation.

Open communication, open access to the data and multidisciplinary interpretation of the cases became so persuasive that citizens started to react in a diversity of ways. They influenced the new composition of local city council through democratic voting establishing an attitude towards health and a health driven, self-regulating city eco-system. Citizens gathered in work groups, overcoming even cultural differences produced and still resident in the competitive money based system, to work together on the application or invention of new air quality and health driven innovations. In a short time a number of entrepreneurial initiatives arose that contribute to health or air quality. These innovations have been developing positively in the economic system through new patterns of growth. It shows empirically that growth itself is not the problem of the reigning system's complexity but the manipulated avoidance of specific entities to accept harmonizing change is. Once this is overcome a new system's dynamics appears that places human values at the kernel of decisions, not banking interest, producing even a healthy circular economy as opposed to a destructive one. AiREAS proved to be a catalyst by introducing the value driven STIR loop and capitalizing the results in economics, politics, humanitarian and ecological wellness, all at the same time.

Within two years after introducing the sustainocratic venture and measurement system, visualizing the invisible to provoke dialogues, various other cities in the Netherlands have now been implementing the same, with their own local Sustainocrats, opening up a new cycle of economic growth alongside their own critical transaction economy. As a consequence, cities from all over Europe and even China are considering to take responsibility and to implement Sustainocratic ventures such as AiREAS for healthy city development as well. A new area of scientific reporting emerged bridging various fragmented scientific specializations into a holistic combination around evolutionary human values. Papers are being written to make the effort known worldwide and serve the community with a proven alternative that can be used to address critical local issues, producing unique innovations that can be expanded across the world. In Eindhoven the program of making visible the invisible locally through the Sustainocratic positioning did not only show the detailed air pollution patterns. It also gave insight into the legal and operational impediments of the current societal system purely based on growth with the economic interaction of fragmented responsibilities. The individual partners had to solve these internal issues in their own organization in order to be able to commit and make the commitment come to a trustworthy contribution to the entire group.

\section{Conclusions}

The engagement with a powerful system such as consumption capitalism and economic growth does not allow players to easily disengage by themselves. There is too much at stake, even when the dramatic consequences of upholding the system are known and recognized. Letting go of the system without viable alternative to transform into would produce as much collapse as when holding on to it. With the definition of sustainocratic ventures complex issues can be addressed without immediately having to sacrifice the complexity of reigning layers of authority. We just change the content of dialogue by adding purpose and direction that no one can neglect. The composition of the group then needs to be exactly the opposite of what we have been used to. Instead of transaction and remedy driven action between fragmented interests, responsibility and value driven action, uniting fragmented talents and authorities into a multidisciplinary platform, takes over. When finishing a common project the fragments dissolve again into their traditional role in the money driven system carrying with them the tangible values created together and individually. The subsequent new growth in the system and the incremental step-by-step approach help improve the global harmony that was lost. The first phase of AiREAS established already three key values for global expansion:

- The proof of concept of a sustainocratic cooperative

- The intense lessons learned when establishing and operating such multidisciplinary commitment for the first time

- The fine maze, low cost, air quality measurement system

- The effect on society when "visualizing the invisible".

AiREAS has no personnel, nor resources of it own, just what the participants contribute and the measurable values that are created and governed by the partners of AiREAS. The expansion worldwide is done by the partners, through a royalty system, creating a circular economy back to where the values originated. With such independent funding next steps can be organized without dependence on public or private means. Hence, the transformation economy has gradually been developing its own income and social structure through integrating the economy of growth while addressing continuous challenges within human, value 
driven changes. The cycle of the STIR Loop (figure 2) and its circular transformative economy (figure 3 ) can be walked through as a self aware cyclic pattern as often as needed to harmonize the local community. In fact, according to the author, it will become an ongoing process that will gradually gain acceptance when humankind has become aware that it needs to take this evolutionary step away from destructive greed into addressing constructive harmonization. In view of the current amount of global issues with the many local consequences we face, it can be foreseen that the human complexity around self-aware harmonization through voluntary patterns of value driven change will rapidly become more important than economic growth. The positioning of Sustainocracy with its ventures like AiREAS is just a start, a proof of principle. The further engagement is an evolutionary resonance with spirituality through the real meaning of life and progress, with our moral evolutionary complexity challenging positively our organizational complexity, calibrating when necessary our actions against the authority of modern holistic knowledge, ethics and responsibilities instead of fragmented expressions of (financial) greed and desires for control. The human complexities hence becomes redefined, understood and implemented for the preservation of our kind within the self aware context of an every changing universal, living environment. 